\title{
Accuracy and precision of total mixed rations fed on commercial dairy farms
}

\author{
A. D. Sova, ${ }^{*}$ S. J. LeBlanc, $†$ B. W. McBride, $\ddagger$ and T. J. DeVries*1 \\ *Department of Animal and Poultry Science, University of Guelph, Kemptville Campus, 830 Prescott Street, Kemptville, ON, K0G 1J0, Canada \\ †Department of Population Medicine, and \\ ‡Department of Animal and Poultry Science, University of Guelph, 50 Stone Road E., Guelph, ON, N1G 2W1, Canada
}

\begin{abstract}
Despite the significant time and effort spent formulating total mixed rations (TMR), it is evident that the ration delivered by the producer and that consumed by the cow may not accurately reflect that originally formulated. The objectives of this study were to (1) determine how TMR fed agrees with or differs from TMR formulation (accuracy), (2) determine daily variability in physical and chemical characteristics of TMR delivered (precision), and (3) investigate the relationship between daily variability in ration characteristics and group-average measures of productivity [dry matter intake (DMI), milk yield, milk components, efficiency, and feed sorting] on commercial dairy farms. Twenty-two commercial freestall herds were visited for 7 consecutive days in both summer and winter months. Fresh and refusal feed samples were collected daily to assess particle size distribution, dry matter, and chemical composition. Milk test data, including yield, fat, and protein were collected from a coinciding Dairy Herd Improvement test. Multivariable mixed-effect regression models were used to analyze associations between productivity measures and daily ration variability, measured as coefficient of variation (CV) over 7 d. The average TMR [crude protein $=16.5 \%$, net energy for lactation $\left(\mathrm{NE}_{\mathrm{L}}\right)=1.7 \mathrm{Mcal} / \mathrm{kg}$, nonfiber carbohydrates $=41.3 \%$, total digestible nutrients $=$ $73.3 \%$, neutral detergent fiber $=31.3 \%$, acid detergent fiber $=20.5 \%, \mathrm{Ca}=0.92 \%, \mathrm{P}=0.42 \%, \mathrm{Mg}=0.35 \%$, $\mathrm{K}=1.45 \%, \mathrm{Na}=0.41 \%]$ delivered exceeded TMR formulation for $\mathrm{NE}_{\mathrm{L}}(+0.05 \mathrm{Mcal} / \mathrm{kg})$, nonfiber carbohydrates $(+1.2 \%)$, acid detergent fiber $(+0.7 \%)$, Ca $(+0.08 \%), \mathrm{P}(+0.02 \%), \mathrm{Mg}(+0.02 \%)$, and $\mathrm{K}(+0.04 \%)$ and underfed crude protein $(-0.4 \%)$, neutral detergent fiber $(-0.6 \%)$, and $\mathrm{Na}(-0.1 \%)$. Dietary measures with high day-to-day $\mathrm{CV}$ were average feed refusal rate $(\mathrm{CV}$ $=74 \%)$, percent long particles $(\mathrm{CV}=16 \%)$, percent medium particles $(\mathrm{CV}=7.7 \%)$, percent short particles $(\mathrm{CV}=6.1 \%)$, percent fine particles $(\mathrm{CV}=13 \%), \mathrm{Ca}$
\end{abstract}

Received April 22, 2013

Accepted September 12, 2013.

${ }^{1}$ Corresponding author: tdevries@uoguelph.ca
$(\mathrm{CV}=7.7 \%), \mathrm{Mg}(\mathrm{CV}=5.2 \%)$, and $\mathrm{Na}(\mathrm{CV}=10 \%)$. Every 0.5 -percentage-point decrease in daily $\mathrm{NE}_{\mathrm{L}}(\mathrm{CV}$ $=1.2 \pm 0.4 \%$ ) was associated with $3.2 \mathrm{~kg} / \mathrm{d}$ greater milk yield, $1.0 \mathrm{~kg} / \mathrm{d}$ greater DMI, and $4.3 \%$ greater efficiency of production. Every 5-percentage-point decrease in variability in percent long particles (average percent long $=19.8 \pm 6.5 ; \mathrm{CV}=16.1 \pm 6.9 \%$ ) in the TMR was associated with $1.2 \mathrm{~kg} / \mathrm{d}$ greater milk yield and a $2.6 \%$ increase in efficiency of milk production. These results demonstrate the importance of ensuring TMR consistency to maximize DMI, production, and efficiency.

Key words: ration variability, total mixed ration, feed sorting, milk production

\section{INTRODUCTION}

Dairy producers are increasingly mindful of factors affecting efficiency of milk production and ultimately their profit margin. Total mixed rations were introduced as a means of providing a consistent supply of nutrients to rumen microbes to optimize rumen function and improve the efficiency of nutrient utilization (Coppock et al., 1981). Variation in ration composition is unavoidable; it was speculated by Stone (2008) that this variability may affect health and production, including incidence of displaced abomasums and fluctuations in average daily milk yield. Provision of a consistent ration, with respect to both physical and chemical composition, is, in theory, an essential part of maximizing cow performance and getting the best value out of the ration.

Inconsistencies in nutrient intake have many causes. Sorting of a TMR can result in cows consuming a ration with a different nutrient composition than that delivered (Leonardi and Armentano, 2003), which has been shown to affect production at the herd level (Sova et al., 2013). Even if cows consume a TMR with high consistency (i.e., no sorting), the ration delivered may not reflect the ration formulated by the nutritionist, nor be consistent in composition from day to day. Recent audits of feeding programs on commercial farms suggest that variability in TMR consistency, which can be influenced by nutrient variability, mixing equipment 
condition, and ingredient mixing order, plays a large role in production efficiency and overall herd profitability (Mikus, 2012). Ration composition can vary from day to day as a result of transient changes in individual ingredient DM and overall ration DM content. Recent work has shown that inflicting these short-term changes in silage DM content may have short-term effects on DMI and milk yield; however, cows quickly adapt to these dietary changes (McBeth et al., 2013). Regardless, measures to reduce daily variability in the TMR, including regular feed analyses, accurate batch preparation, and education of people preparing the ration, should be taken to ensure maximum herd health and profitability (Stone, 2008).

The objectives of this study were to (1) determine the degree to which TMR fed differs from ration formulation (accuracy), (2) determine the daily variability in nutrient and physical characteristics of TMR (precision), and (3) examine associations between daily variability in ration characteristics and productivity measures, including milk yield, milk components, DMI, efficiency of milk production, and feed sorting on commercial farms.

\section{MATERIALS AND METHODS}

\section{On-Farm Data Collection}

A total of 24 commercial dairy farms in eastern Ontario, Canada, were enrolled in this cross-sectional study. This was completed as part of a larger study investigating the relationship between feed sorting, feeding management, and productivity measures of freestall-housed dairy cows; see Sova et al. (2013) for detailed methods. In summary, a list of eligible farms was identified by CanWest DHI (Guelph, Ontario, Canada) based on suitability criteria: primarily Holstein genetics, lactating herd size $>50$ cows, freestall housing, and location (within $150 \mathrm{~km}$ of Kemptville, Ontario, Canada). Those farms that met the criteria and conveyed interest in participation were enrolled. Two farms were excluded from the study, one during the data collection period, due to time commitments, and one before analysis, as sampling and recording protocols were not met. In total, 22 farms were included in the analysis.

Average lactating herd size and group study size were $162 \pm 120$ and $83 \pm 32$ (mean $\pm \mathrm{SD}$ ), respectively. Those 22 farms were visited for 7 consecutive days in each of summer (June-September) and winter (December-March). Summer data collection was split over 2 yr; 9 farms were studied in the summer of 2011 and the remaining 13 in the summer of 2012. All 22 farms were visited in the winter of 2011 to 2012. Data collection was limited to one feeding group per farm, where the focal group consisted of the highest producing group of cows with an even distribution of DIM and parity, and a group size $>50$ cows (or $>40 \%$ of the total lactating herd population). Groups composed of primarily fresh and first-lactation cows were excluded from selection.

Data collection was scheduled to coincide with a monthly DHI test $( \pm 3 \mathrm{~d})$. Milk production data, including milk yield, fat, protein, MUN, and SCC, as well as cow characteristics including DIM and parity, were collected and summarized by group. Daily grouplevel DMI was measured by subtracting feed refusal amount from the amount of feed dispensed from the TMR mixer wagon. Amount delivered was calculated by recording the initial TMR scale weight and subtracting any balance after feed was delivered to the focal group. Daily samples of fresh and refusal TMR were taken at the time of delivery and $24 \mathrm{~h}$ after delivery, respectively. Two samples were taken of each fresh and refusal feed, one to assess DM and one to assess particle size. Fresh samples were collected from the feed bunk at 6 to 10 spots during feed delivery to ensure collection of a representative sample. Refusal samples were collected at the time of feed bunk clean-up and before fresh feed delivery. Refusal samples were collected from 6 to 10 handfuls from the thoroughly mixed refusal feed to ensure a representative sample of the leftover feed. Additional fresh samples were collected and recorded by the herd manager in cases of multiple daily feeding events. Herd managers were trained to collect samples following the protocol above. In the case of multiple feedings, duplicate samples were assessed separately and then pooled equally before laboratory analysis. Samples taken to assess particle size were separated with a Penn State Particle Separator (PSPS; Kononoff et al., 2003), which separated samples into 4 fractions: long $(>19 \mathrm{~mm})$, medium $(<19,>8 \mathrm{~mm})$, short $(<8$, $>1.18 \mathrm{~mm})$, and fine $(<1.18 \mathrm{~mm})$ particles. Samples taken for DM and particle size were oven-dried at $55^{\circ} \mathrm{C}$ for $48 \mathrm{~h}$ and then ground to pass through a 1-mm screen (Brinkmann mill, Brinkmann Instruments Co., Westbury, NY). All dried samples of the fresh (fed) TMR, plus the dried TMR particle fractions, were sent to Cumberland Valley Analytical Services Inc. (Maugansville, MD) for analysis of $\mathrm{DM}\left(135^{\circ} \mathrm{C}\right.$; AOAC International, 2000; method 930.15), ash $\left(535^{\circ} \mathrm{C}\right.$; AOAC International, 2000; method 942.05), ADF (AOAC International, 2000; method 973.18), NDF with heatstable $\alpha$-amylase and sodium sulfite (Van Soest et al., 1991), $\mathrm{CP}(\mathrm{N} \times 6.25$; AOAC International, 2000; method 990.03; Leco FP-528 Nitrogen Analyzer, Leco, St. Joseph, MI), and minerals (AOAC International, 2000; method 985.01). Net energy for lactation and TDN were calculated based on NRC (2001) equations. 
Nonfiber carbohydrates were calculated as follows: 100 $-(\% \mathrm{CP}+\% \mathrm{NDF}+\%$ fat $+\%$ ash $)$. Refusal samples were analyzed at University of Guelph- Kemptville Campus using an Ankom ${ }^{2000}$ Fiber Analyzer (Ankom Technology, Macedon, NY) for NDF with heat-stable

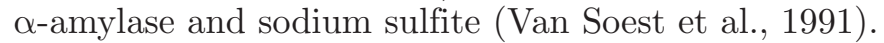

A questionnaire on housing and feeding management practices was administered by personal interview of the herd manager during the week of data collection for each season. A copy of the most recent TMR formulation was obtained as part of this questionnaire for each season; this formulation included a breakdown of the expected TMR nutrient composition $\left(\mathrm{CP}, \mathrm{NE}_{\mathrm{L}}, \mathrm{NFC}\right.$, $\mathrm{NDF}, \mathrm{ADF}, \mathrm{Ash}, \mathrm{Ca}, \mathrm{P}, \mathrm{Mg}, \mathrm{K}, \mathrm{Na}$, and trace minerals).

\section{Calculations and Statistical Analysis}

Coefficients of variation (CV) between the formulated ration and ration delivered were calculated for $\mathrm{CP}, \mathrm{ADF}, \mathrm{NDF}$, ash, $\mathrm{Ca}, \mathrm{P}, \mathrm{Mg}, \mathrm{K}, \mathrm{Na}, \mathrm{Fe}, \mathrm{Mn}, \mathrm{Zn}$, $\mathrm{Cu}, \mathrm{NE}_{\mathrm{L}}, \mathrm{TDN}$, and NFC. This was calculated by dividing the standard deviation (SD) between the formulated value (constant over $7 \mathrm{~d}$ ) and the average analyzed value (across the $7 \mathrm{~d}$ ) by the average of those values (fed and formulated over $7 \mathrm{~d}$ ) and expressed as a percentage. Differences between the TMR fed and formulated were calculated by subtracting the formulated value from the value obtained from laboratory analysis.

Daily ration variability, as expressed by $\mathrm{CV}$, was calculated over each 7-d period, within each farm in both winter and summer periods, for nutrients, including $\mathrm{CP}, \mathrm{ADF}, \mathrm{NDF}$, ash, $\mathrm{Ca}, \mathrm{P}, \mathrm{Mg}, \mathrm{K}, \mathrm{Na}, \mathrm{Fe}, \mathrm{Mn}, \mathrm{Zn}$, $\mathrm{Cu}, \mathrm{NE}_{\mathrm{L}}, \mathrm{TDN}$, and $\mathrm{NFC}$, and physical characteristics, including particle size distribution, DM, refusal rate, physically effective fiber (pef), and physically effective NDF (peNDF). The CV were calculated by dividing the SD of each nutrient over $7 \mathrm{~d}$ by the average of those values over $7 \mathrm{~d}$ and was expressed as a percentage. The pef was determined as the DM proportion of particles retained by the top 2 sieves of the PSPS (Yang and Beauchemin, 2006). The peNDF was calculated by multiplying the NDF content of the feed by the pef. Refusal rate was calculated by dividing the DM refused by the DM offered and multiplying by $100 \%$.

Sorting for each particle fraction of the PSPS was calculated as the actual intake of each fraction expressed as a percentage of the predicted intake of that fraction (Leonardi and Armentano, 2003). The predicted intake of an individual fraction was calculated as the product of the group level DMI of the total diet multiplied by the DM percentage of that fraction in the fed TMR. Values equal to $100 \%$ indicate no sorting, $<100 \%$ indicate selective refusals (sorting against), and $>100 \%$ indicate preferential consumption (sorting for).
Before analyses, outcomes were screened for normality using the UNIVARIATE procedure of SAS (SAS Institute, 2009). Data were summarized by farm and period (summer and winter) to obtain herd-level averages for the outcomes of interest (milk yield, fat, protein, DMI, efficiency of milk production, and feed sorting). Associations between those outcomes and variability $(\mathrm{CV})$ in ration components $\left(\mathrm{CP}, \mathrm{ADF}, \mathrm{NDF}, \mathrm{NE}_{\mathrm{L}}\right.$, NFC, ash, Ca, P, Mg, Na, K, DM, pef, peNDF, particle size distribution) were analyzed with multivariable linear mixed models using the MIXED procedure of SAS (SAS Institute, 2009), treating period as a repeated measure. These models were constructed with the intent of purely describing associations, and not ascribing any causality in the relationships observed. Farm within period was included in the model as the subject of the repeated statement. The covariance structure used in the repeated statement was compound symmetry, chosen based on best fit according to Schwarz's Bayesian information criterion. All independent variables were screened in univariable models; those variables with $P \leq 0.25$ were retained for the multivariable linear regression modeling (Dohoo et al., 2009). The CORR procedure of SAS was used to determine the level of correlation between the retained explanatory variables. In cases where 2 variables were correlated $(\mathrm{r}>0.6)$, the one with the most biological plausibility was retained for the multivariable model. For the multivariable models, effects were considered significant at $P<0.05$ and tendencies at $P \leq 0.1$. Manual backward elimination of nonsignificant and nontrending effects was used to construct the final multivariable models.

\section{RESULTS AND DISCUSSION}

\section{Ration Variability}

The degree of agreement between the fed and formulated rations is given in Table 1 . On average, the fed ration did not accurately represent the formulated ration. Specifically, $>5 \%$ CV was observed for all nutrient components with the exception of DM, CP, $\mathrm{TDN}$, and $\mathrm{NE}_{\mathrm{L}}$ (Table 1). The greatest variability between fed and formulated was observed for ash, Ca, $\mathrm{Na}$, and trace minerals (Table 1 ). The average TMR delivered exceeded formulation for $\mathrm{NE}_{\mathrm{L}}, \mathrm{NFC}, \mathrm{ADF}$, $\mathrm{Ca}, \mathrm{P}, \mathrm{Mg}$, and $\mathrm{K}$, and underfed $\mathrm{CP}, \mathrm{NDF}$, and $\mathrm{Na}$ (Table 1). On average, these differences were small, but variability between farms, as indicated by large ranges, was evident (Table 1). Potential for herd-level effects related to these discrepancies exist, especially for those farms with larger margins of error. Previous research has reported positive quadratic relationships between milk yield, milk protein yield, and ration $\mathrm{CP}$ content 
(Colmenero and Broderick, 2006). As such, it would be expected that farms with larger discrepancies between the fed and formulated rations would see greater reductions in productivity measures. To put it into perspective, of the 22 farms, 4 farms underfed $\mathrm{CP}$ by at least 1 percentage unit and 11 farms under- or overfed NDF by more than 2 percentage units. Overall, differences between the fed and formulated diets were observed on all study farms, indicating that more attention should be paid to the composition of the final TMR. Recent work has stressed the importance of targeting NRC requirements; for example, overfeeding minerals leads to excretion into the environment and may subsequently affect the surrounding environment (Castillo et al., 2013). In a study by Castillo et al. (2013), the average diet fed contained 1.3 times the NRC requirement for phosphorus, which poses implications for environmental sustainability due to nutrient excretion. In our study, it was impossible to state the individual effects of nutrient excess or deficiencies experienced on each farm, but future research in a controlled setting may improve our understanding of the effect of such deviations from formulation

Average and day-to-day variability of physical and chemical composition of the TMR fed are given in Tables 2 and 3, respectively. Table 2 demonstrates average daily variability in the physical composition of the ration. Greater than 5\% CV in day-to-day variability was observed for refusal rate, percent long particles, percent medium particles, percent short particles, percent fine particles, and peNDF (Table 2). Day-to-day variability in the nutrient composition of the ration is found in Table 3 . The greatest daily variability was observed for $\mathrm{Ca}, \mathrm{Mg}, \mathrm{Na}$, and trace minerals (Table 3 ). The range in daily variability for both physical and nutrient composition was wide between individual farms (Tables 2 and 3$)$.

To our knowledge, a limited number of published studies have quantified the precision or accuracy of commercial farm feeding and associated implications for production. James and Cox (2008) suggested that rising costs of feed ingredients dictate the need for more rigid monitoring of nutrient balances, also termed precision feeding. They distinguished between the use of precise and accurate feeding, stating that precision refers to consistency between days, whereas accuracy pertains to how well the fed ration meets the specifications formulated by the nutritionist. The results of our study suggest that commercial rations in the observed herds were delivered more precisely than accurately, because the variability observed between the fed and formulated rations was higher than the observed dayto-day variability. However, for macronutrients, the $\mathrm{CV}$ of discrepancies between formulation and delivered TMR and day-to-day variation in the TMR delivered were all less than $10 \%$ and mostly less than $5 \%$. James and Cox (2008) also reported that commercial rations lacked precision and accuracy, with variability being at-

Table 1. Degree of agreement between fed and formulated TMR on 22 commercial dairy farms ${ }^{1}$

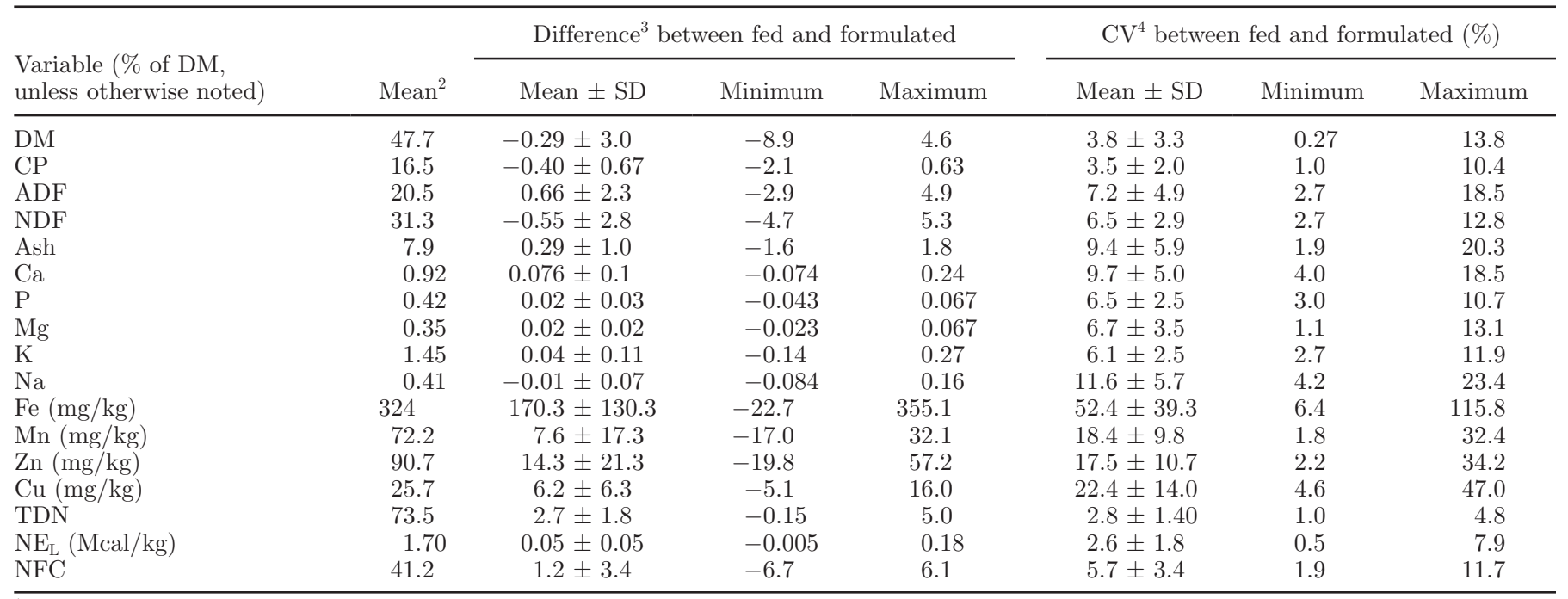

${ }^{1}$ Twenty-two commercial dairy farms were visited for 7 consecutive days in summer and winter months; fresh TMR samples were collected daily for 7 consecutive days in each period, and data were averaged for each farm and period $(\mathrm{n}=44 ; 22$ observations $\times 2$ periods).

${ }^{2}$ Mean $=$ average value delivered in the ration over $7 \mathrm{~d}$.

${ }^{3}$ Difference $=$ nutrient composition of fed ration - formulated nutrient composition; negative values indicate deficiencies compared with the TMR formulated by the nutritionist.

${ }^{4} \mathrm{CV}=(\mathrm{SD}$ between average value fed and formulated/average of value fed and formulated $) \times 100$. 
Table 2. Day-to-day variability in ration characteristics on 22 commercial dairy farms $^{1}$

\begin{tabular}{|c|c|c|c|c|c|c|c|}
\hline Variable & Mean $^{2}$ & \multicolumn{3}{|c|}{$\mathrm{SD}^{3}$} & \multicolumn{3}{|c|}{$\mathrm{CV}^{4}(\%)$} \\
\hline $\mathrm{DM}(\%)$ & 47.7 & $1.7 \pm 0.8$ & 0.74 & 3.8 & $3.6 \pm 1.5$ & 1.6 & 7.5 \\
\hline Percent long particles & 19.8 & $2.9 \pm 0.8$ & 0.86 & 4.2 & $16.1 \pm 6.9$ & 8.1 & 31.0 \\
\hline Percent medium particles & 34.3 & $2.5 \pm 0.9$ & 1.3 & 5.0 & $7.7 \pm 4.1$ & 3.1 & 22.1 \\
\hline Percent short particles & 35.5 & $2.1 \pm 0.9$ & 0.74 & 4.8 & $6.1 \pm 3.2$ & 1.9 & 17.3 \\
\hline
\end{tabular}

${ }^{1}$ Twenty-two commercial dairy farms were visited for 7 consecutive days in summer and winter months; fresh TMR samples were collected daily for 7 consecutive days in each period, and data were averaged for each farm and period ( $\mathrm{n}=44 ; 22$ observations $\times 2$ periods).

${ }^{2}$ Mean $=$ average value delivered in the ration over $7 \mathrm{~d}$.

${ }^{3}$ Standard deviation over $7 \mathrm{~d}$.

${ }^{4} \mathrm{CV}=(\mathrm{SD}$ over $7 \mathrm{~d}$ /average value over $7 \mathrm{~d}) \times 100$.

${ }^{5}$ Refusal rate $=($ DM refused $/$ DM offered $) \times 100$.

${ }^{6}$ pef $=$ physical effectiveness factor measured as the sum of the DM proportions retained on the top 2 Penn State particle sieves.

${ }^{7}$ peNDF $=$ physically effective NDF measured by multiplying pef by NDF (\% DM) content of the ration.

tributed to operator errors, equipment failure, and poor layout of the feed loading area. Interestingly, James and Cox (2008) reported that secondary feed workers, those responsible for TMR mixing less than $25 \%$ of the time, were more accurate than those primary feeders, likely because those doing it routinely developed bad mixing practices. We did not record the number of feed workers, so it was not possible to further explore this hypothesis, but the majority of farms in our study had one person primarily responsible for batch preparation. Regardless, regular monitoring of between-batch vari- ability is likely helpful in evaluating operator accuracy and ensuring delivery of a consistent ration.

It is widely accepted that errors in mixing can result in variable ration composition, yet a limited amount of work has quantified the degree of agreement between fed and formulated rations on commercial farms. Cox (2007) reported that the phosphorus (P) content of the ration, which was correlated to $\mathrm{CP}$ content, was significantly different than the value formulated by the nutritionist; farms with higher formulated values for $\mathrm{P}$ were more likely to underfeed $\mathrm{P}$, whereas those

Table 3. Day-to-day variability in TMR nutrient composition on 22 commercial dairy farms ${ }^{1}$

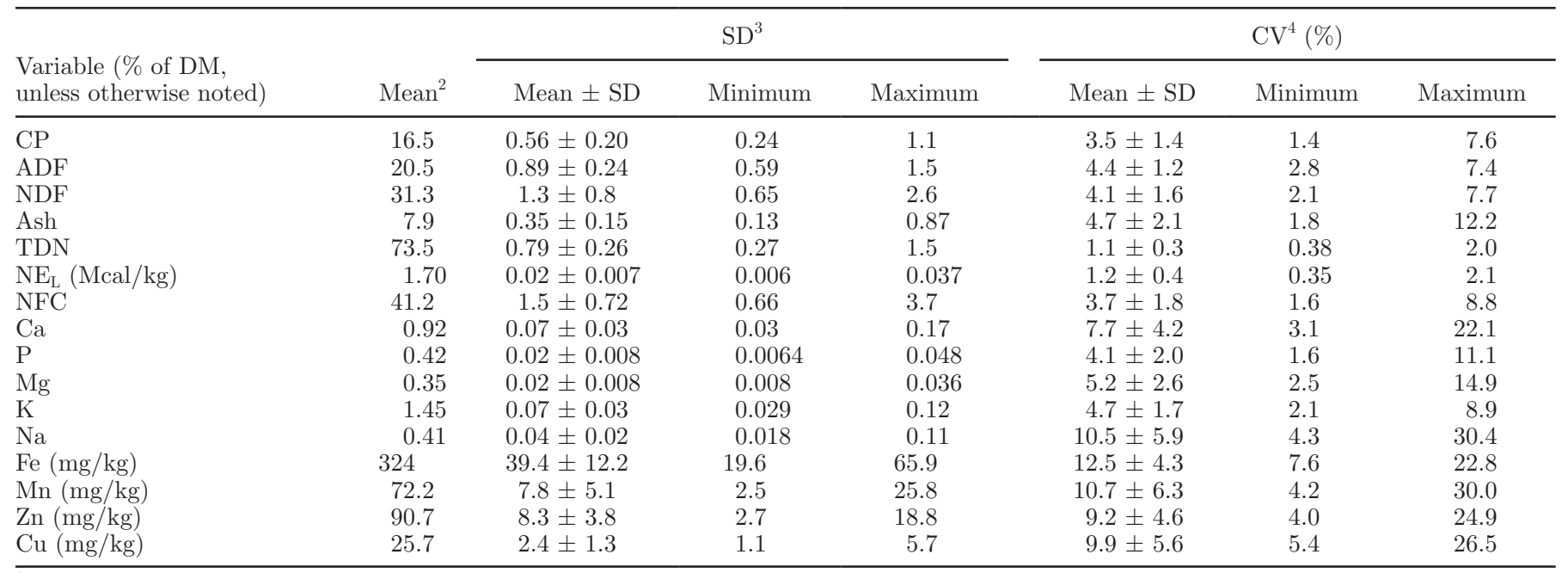

${ }^{1}$ Twenty-two commercial dairy farms were visited for 7 consecutive days in summer and winter months; fresh TMR samples were collected daily for 7 consecutive days in each period, data were averaged for each farm and period $(\mathrm{n}=44 ; 22$ observations $\times 2$ periods).

${ }^{2}$ Mean $=$ average value delivered in the ration over $7 \mathrm{~d}$.

${ }^{3}$ Standard deviation over $7 \mathrm{~d}$.

${ }^{4} \mathrm{CV}=(\mathrm{SD}$ over $7 \mathrm{~d}$ /average value over $7 \mathrm{~d}) \times 100$. 
that formulated for lower $\mathrm{P}$ values were more likely to overfeed P. An evaluation of rations fed on commercial dairy farms in California indicated considerable variation $(\mathrm{CV}>5 \%)$ between the fed and formulated ration, particularly for fat, NDF, Ca, and CP (Silva-del-Rio and Castillo, 2012). Variation in the nutrient composition and DM content of forages are often the main culprits explaining variability between batches of TMR; it has been speculated that production effects may arise due to this variability (Buckmaster and Muller, 1994). However, more recent controlled research reveals that short-term changes in individual forage DM may have little effect on milk yield, DMI, and milk composition (McBeth et al., 2013). Those researchers noted that transient changes in silage DM reduced DMI during the short-term treatment periods, but cows adapted to dietary changes during subsequent days (McBeth et al., 2013). Regardless, these findings suggest that increased surveillance of the TMR composition, not only of individual feed ingredients, may be helpful as a regular component of feeding management to ensure delivery of TMR with the intended nutrient composition to maintain production and feed intake.

\section{Factors Associated with DMI}

Group-average DMI was (mean \pm SD) $24.3 \pm 2.1$ $\mathrm{kg} / \mathrm{d}$ (Sova et al., 2013). Reduced variability in $\mathrm{NE}_{\mathrm{L}}$ ration content was associated with greater DMI $(P=$ 0.005 ); every 0.5 -percentage-point increase in $\mathrm{NE}_{\mathrm{L}}$ variability (CV) was associated with a reduction in DMI of $1.0 \mathrm{~kg} / \mathrm{d}$. Variability in $\mathrm{NE}_{\mathrm{L}}$ content of the ration was correlated $(\mathrm{r}>0.6)$ with other nutrient variabilities in the ration, including ash, $\mathrm{ADF}, \mathrm{NDF}, \mathrm{TDN}$, and NFC (data not shown). Accordingly, among these, only $\mathrm{NE}_{\mathrm{L}}$ was included in the multivariable model. Given the collinearity in the variability in these nutrients, it is logical to assume that DMI could also be negatively affected by increased variability in those other nutrients. In this study we found that increased DMI was associated with more frequent feed delivery $(2 \times$ vs. $1 \times /$ d; Sova et al., 2013). Farms feeding $2 \times / d$ had $\mathrm{NE}_{\mathrm{L}}$ CV of $1.0 \%$, whereas farms feeding $1 \times / \mathrm{d}$ had $\mathrm{CV}$ of $1.3 \%$, but the difference was not significant $(P=0.13)$. Because of this, it could be hypothesized that the association between reduced variability in NEL and DMI was driven, in part, by the association between feeding frequency and DMI.

\section{Factors Associated with Milk Production Parameters}

Group-average milk yield, 4\% FCM, and ECM were $34.3 \pm 5.9,33.2 \pm 5.2$, and $35.6 \pm 5.4 \mathrm{~kg} / \mathrm{d}$ (mean \pm SD), respectively (Sova et al., 2013). Greater test-day milk yield was associated with greater variability in refusal rate and lower variability in percent long particles and $\mathrm{NE}_{\mathrm{L}}$ (Table 4). Controlling for the effects of crop season (2011 vs. 2012), greater $4 \% \mathrm{FCM}$ was also associated with greater variability in refusal rate $(P=$ $0.005)$, and lower variability in percent long particles in the fed ration $(P=0.022)$ and $\mathrm{NE}_{\mathrm{L}}(P<0.001)$. Every 20-percentage-point increase in refusal rate variability (CV) was associated with $1.3 \mathrm{~kg} / \mathrm{d}$ greater milk yield and $1.2 \mathrm{~kg} / \mathrm{d}$ greater $4 \%$ FCM yield. Every 0.5 -percentage-point increase in variability of $\mathrm{NE}_{\mathrm{L}}$ was associated with $3.2 \mathrm{~kg} / \mathrm{d}$ lesser milk yield (Figure 1). Every 5-percentage-point increase in $\mathrm{CV}$ of percent long particles in the fed ration was associated $1.2 \mathrm{~kg} / \mathrm{d}$ lesser milk yield. Average refusal rate was $3.5 \% \pm 2.1$ (Sova et al., 2013). Those farms with the greatest CV for refusal rate also had much lower refusal rates on average $(<2 \%)$. However, lower refusal rates were not associated with greater milk yield or DMI (Sova et al., 2013), although greater refusal rate variability was. This suggests that the association we found between refusal rate variability and milk yield (Table 4) might be attributed to the management style of those farms. James and Cox (2008) reported a similar association in regard to milk yield, with increased deviation in daily loads $(\mathrm{kg} / \mathrm{d})$ negatively correlated with milk production. These deviations were attributed to errors in under- and overfeeding, particularly for CP. Additionally, increased variation in milk yield has been linked to periods of poor feeding management, as a result of errors in ingredient DM monitoring (Tylutki et al., 2004).

Group-average milk fat percentage (mean \pm SD) was $3.75 \pm 0.23$ (Sova et al., 2013). Controlling for the effect of season, greater milk fat percentage was associated with greater variability in percent long particles in the fed ration (Table 5) and greater milk fat yield was associated with less variability in $\mathrm{NE}_{\mathrm{L}}(P=0.001)$. Every 5 -percentage-point increase in variability in percent long particles in the fed ration was associated with a 0.06 -percentage-point increase in milk fat percentage. No association between percent long particles in the ration and milk fat percentage was observed (Sova et al., 2013), which suggests that consistency in particle size inclusion has a greater effect on milk composition than the absolute proportion of long particles. However, there are likely thresholds beyond which the percent long particles and NDF content of the ration would affect milk fat percentage (Mertens, 1997). One of the intended benefits of feeding a TMR is to maintain consistent rumen conditions to maximize efficiency of nutrient conversion (Coppock et al., 1981). The current findings substantiate this claim because increased variability in particle size distribution was associated with milk of lower compositional value. 
568

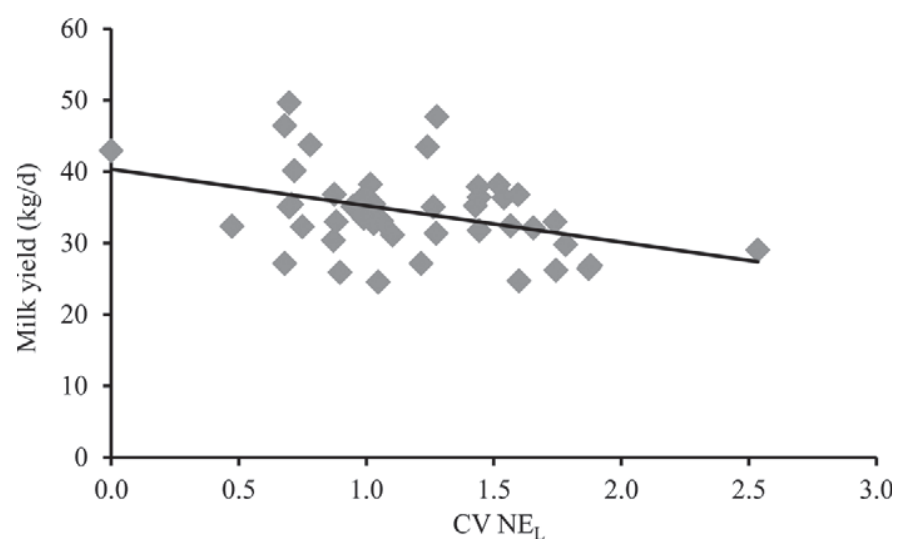

Figure 1. Association between fed ration coefficient of variation $(\mathrm{CV})$ in $\mathrm{NE}_{\mathrm{L}}$ and average test-day milk yield. Data were collected on 22 farms for 7 consecutive days in summer and winter months. The $\mathrm{CV}$ was calculated for each farm and period as the standard deviation of $\mathrm{NE}_{\mathrm{L}}$ over $7 \mathrm{~d}$ divided by the average $\mathrm{NE}_{\mathrm{L}}$ over $7 \mathrm{~d}$.

Group-average milk protein percentage (mean \pm SD) was $3.24 \pm 0.15$ (Sova et al., 2013). Controlling for the effect of season, greater milk protein percentage was associated with increased variability in percent short particles in the TMR, and reduced variability in percent fine particles and CP (Table 5). Every 2-percentage-point increase in variability of percent short particles in the fed ration was associated with 0.03-percentage-point increase in milk protein percentage. Every 2-percentagepoint reduction in variability of percent fine particles and $\mathrm{CP}$ was associated with 0.02 - and 0.06 -percentagepoint increases in milk protein percentage, respectively. Variability in percent short particles was also modestly correlated with percent medium and fine particles $(\mathrm{r}=$ 0.47 and $\mathrm{r}=0.43$, respectively), which suggests that increased variability in those particles may also negatively affect milk protein percentage.
Group-level efficiency of test-day milk yield, $4 \%$ FCM, and ECM were $1.41 \pm 0.16,1.36 \pm 0.13$, and $1.46 \pm 0.13 \mathrm{~kg}$ of milk $/ \mathrm{kg}$ of DMI (mean $\pm \mathrm{SD}$ ), respectively (Sova et al., 2013). Greater efficiency of test-day milk yield was associated with increased variability in refusal rate and decreased variability in $\mathrm{NE}_{\mathrm{L}}$ (Table 4). Refusal rate was not associated with efficiency of milk production (Sova et al., 2013). Interestingly, we observed an association between variability in refusal rate and milk yield (Table 4) but no association with DMI, meaning that greater milk yield was responsible for the increase in efficiency. As speculated earlier, some aspect of management style could explain this finding. Farms targeting lower feed wastage could be expected to have greater variability in refusal rate as they attempted to fine-tune feed amounts each day. Such managers were likely employing tactics to reduce economic costs associated with milk production, and might also have implemented more intensive practices to maximize milk yield. This finding could be due to some unmeasured variable, such as culling rate of lowproducing cows. Reduced variability in percent long particles was associated with increased efficiency of test-day milk production (Table 4). Less sorting against long particles was associated with greater efficiency of $4 \%$ FCM production (Sova et al., 2013). From a biological perspective, less sorting against long particles would be conducive to higher rumen pH (DeVries et al., 2008) and, thus, more efficient utilization of nutrients. Similar associations were found for $4 \% \mathrm{FCM}$, with greater $4 \%$ FCM associated with increased variability in refusal rate $(P=0.009)$ and lower variability in $\mathrm{NE}_{\mathrm{L}}$ content $(P=0.006)$ and a tendency to be associated with lower variability in percent long particles in the fed ration $(P=0.053)$. Every 20 -percentage-point increase in refusal rate variability was associated with 2.7 and $2.3 \%$ increases in efficiency of test-day milk production

Table 4. Final multivariable linear regression models for ration variability ${ }^{1}$ factors associated with milk yield and efficiency of milk production ${ }^{2}$

\begin{tabular}{|c|c|c|c|c|c|c|}
\hline \multirow[b]{2}{*}{ Variable } & \multicolumn{3}{|c|}{ Test-day milk yield ${ }^{3}(\mathrm{~kg} / \mathrm{d})$} & \multicolumn{3}{|c|}{$\begin{array}{l}\text { Efficiency of test-day milk yield } \\
\quad(\mathrm{kg} \text { of milk/kg of DMI) }\end{array}$} \\
\hline & $\beta^{4}$ & $\mathrm{SE}$ & $P$-value & $\beta$ & $\mathrm{SE}$ & $P$-value \\
\hline Intercept & 40.69 & 2.83 & $<0.001$ & 1.53 & 0.087 & $<0.001$ \\
\hline $\mathrm{CV}^{5}$ refusal rate & 0.065 & 0.025 & 0.012 & 0.0019 & 0.0008 & 0.017 \\
\hline $\mathrm{CV}^{5}$ long particles & -0.23 & 0.093 & 0.017 & -0.0073 & 0.0029 & 0.015 \\
\hline $\mathrm{CV}^{5} \mathrm{NE}_{\mathrm{L}}$ & -6.33 & 1.72 & $<0.001$ & -0.12 & 0.053 & 0.028 \\
\hline
\end{tabular}

${ }^{1}$ Ration variability $=$ coefficient of variation $(\mathrm{CV})$ of day-to-day variability in the nutrient composition of the TMR.

${ }^{2}$ Data were collected on 22 commercial dairy farms for 7 consecutive days during winter and summer periods ( $\mathrm{n}=44 ; 22$ observations $\times 2$ periods).

${ }^{3}$ Milk yield collected from a coinciding DHI test ( $\pm 3 \mathrm{~d}$ of data collection period).

${ }^{4} \beta=$ estimated regression coefficient.

${ }^{5} \mathrm{CV}=\mathrm{SD}$ over $7 \mathrm{~d}$ /average over $7 \mathrm{~d}$; coefficients $(\beta)$ are per 1-point increase in $\mathrm{CV}$. 
Table 5. Final multivariable linear regression models for ration variability ${ }^{1}$ factors associated with milk fat and protein $^{2}$

\begin{tabular}{|c|c|c|c|c|c|c|}
\hline \multirow[b]{2}{*}{ Variable } & \multicolumn{3}{|c|}{ Milk fat ${ }^{3}(\%)$} & \multicolumn{3}{|c|}{ Milk protein ${ }^{3}(\%)$} \\
\hline & $\beta^{4}$ & $\mathrm{SE}$ & $P$-value & $\beta^{4}$ & $\mathrm{SE}$ & $P$-value \\
\hline Intercept & 3.66 & 0.095 & $<0.001$ & 3.44 & 0.074 & $<0.001$ \\
\hline Period & & & 0.0084 & & & 0.008 \\
\hline Winter & $\operatorname{Ref}^{5}$ & & & Ref & & \\
\hline Summer & -0.21 & 0.076 & & -0.14 & 0.049 & \\
\hline $\mathrm{CV}^{6}$ long particles & 0.012 & 0.0045 & 0.013 & - & - & - \\
\hline $\mathrm{CV}^{6}$ short particles & - & - & - & 0.015 & 0.0061 & 0.017 \\
\hline $\mathrm{CV}^{6}$ fine particles & - & - & - & -0.0087 & 0.004 & 0.036 \\
\hline $\mathrm{CV}^{6} \mathrm{CP}$ & - & - & - & -0.031 & 0.012 & 0.014 \\
\hline
\end{tabular}

${ }^{1}$ Ration variability = coefficient of variation $(\mathrm{CV})$ of day-to-day variability in the nutrient composition of the TMR.

${ }^{2}$ Data were collected on 22 commercial dairy farms for 7 consecutive days during winter and summer periods ( $\mathrm{n}=44 ; 22$ observations $\times 2$ periods).

${ }^{3}$ Milk production parameters collected from a coinciding DHI test $( \pm 3 \mathrm{~d}$ of data collection period).

${ }^{4} \beta=$ estimated regression coefficient.

${ }^{5}$ Ref $=$ reference category.

${ }^{6} \mathrm{CV}=\mathrm{SD}$ over $7 \mathrm{~d}$ /average over $7 \mathrm{~d}$; coefficients $(\beta)$ are per 1-point increase in $\mathrm{CV}$.

and 4\% FCM, respectively. Every 5-percentage-point increase in percent long particle variability was associated with a decrease in efficiency of test-day milk yield and $4 \%$ FCM by 2.6 and 1.6\%, respectively. Every 0.5 -percentage-point increase in $\mathrm{NE}_{\mathrm{L}}$ variability was associated with a decrease in efficiency for both test-day and $4 \%$ FCM by 4.3 and $4.4 \%$, respectively.

Variability in nutrient and DM composition of feed ingredients is inherent and efforts to minimize its effect on TMR variability should be taken (Weiss and St-Pierre, 2009). A variety of tools are available at the farm level for monitoring diet consistency, including the PSPS (Kononoff et al., 2003). Regular monitoring of particle distributions, both within and between batches, can help to detect areas of concern to avoid losses in production. Proper education of TMR operators, regular feed sample analysis, use of premixes and reformulating the ration based on changes in DM can help to reduce diet variability (Stone, 2008). Our findings suggest that lower variability in ration composition may translate to improvements in herd productivity, but the specific methods used to reduce variability on our farms were not measured. Further research regarding TMR operator practices and bunk management will enhance understanding of factors influencing TMR variability on commercial dairy farms.

\section{Factors Associated with Feed Sorting}

On average, cows sorted against long particles and for short and fine particle fractions (Sova et al., 2013); average group-level sorting values were $97 \%$ for long particles and $101 \%$ for both short and fine particles.
Less group-level sorting against long particles was associated with increased variability in refusal rate and reduced variability in percent DM of the fed ration (Table 6). Past research has reported increased (MillerCushon and DeVries, 2009) and decreased (Leonardi et al., 2005) feed sorting as a result of water addition, depending on initial DM percentage of the ration. Our study reported no association between DM content and feed sorting at a group level (Sova et al., 2013). Variability in DM content of individual ration ingredients is often cited as a source of variability in the consistency of TMR (Stone, 2008). Lower sorting in favor of fine particles was associated with increased variability in refusal rate and decreased variability in pef (Table 6). Lower sorting in favor of short particles was associated with increased variability in refusal rate and tended to be associated with increased variability in percent long particles (Table 6). As mentioned previously, greater variability in refusal rate was experienced by herds with low feed wastage $(<2 \%)$. Overall, increased variability in refusal rate and lower feed refusal is associated with less group-level sorting against long particles and for fine particles (Sova et al., 2013). Efforts to minimize sorting for fine particles and against long particles may translate to improvements in milk yield and efficiency of milk production (Sova et al., 2013). Thus, the present findings suggest that more frequent monitoring of particle size distribution and TMR DM content may promote more consistent nutrient consumption, which may translate into greater productivity.

Variability in TMR composition has been widely observed in the industry, yet little research has been published in this field of research. The findings of 
Table 6. Final multivariable linear regression models for ration variability ${ }^{1}$ factors associated with sorting ${ }^{2}$ of TMR particle fractions $^{3}$

\begin{tabular}{|c|c|c|c|c|c|c|c|c|c|}
\hline Variable & \multicolumn{3}{|c|}{ Long particle sorting (\%) } & \multicolumn{3}{|c|}{ Short particle sorting (\%) } & \multicolumn{3}{|c|}{ Fine particle sorting (\%) } \\
\hline Intercept & 97.6 & 1.17 & $<0.001$ & 102.2 & 0.35 & $<0.001$ & 101.7 & 0.38 & $<0.001$ \\
\hline Winter & - & - & - & - & - & - & $\operatorname{Ref}^{5}$ & & \\
\hline Summer & - & - & - & - & - & - & -0.47 & 0.25 & \\
\hline $\mathrm{CV}^{6}$ refusal rate & 0.028 & 0.0092 & 0.0045 & -0.01 & 0.0036 & 0.0073 & -0.012 & 0.004 & 0.004 \\
\hline $\mathrm{CV}^{6} \mathrm{~K}$ & -0.28 & 0.14 & 0.042 & - & - & - & - & - & - \\
\hline
\end{tabular}

${ }^{1}$ Ration variability $=$ coefficient of variation $(\mathrm{CV})$ of day-to-day variability in the nutrient composition of the TMR.

${ }^{2}$ Sorting $=100 \times($ fraction DMI/ predicted fraction DMI $)$ where fraction $=$ long, medium, short, or fine particles. Sorting values equal to $100 \%$ indicate no sorting, $<100 \%$ indicate selective refusal (sorting against), and $>100 \%$ indicate preferential consumption (sorting for). Data were collected on 22 commercial dairy farms for 7 consecutive days during winter and summer periods ( $\mathrm{n}=44 ; 22$ observations $\times 2$ periods).

${ }^{3}$ Particle size determined by Penn State Particle Separator, which has a 19-mm screen (long), 8-mm screen (medium), 1.18-mm screen (short), and a pan (fine).

${ }^{4} \beta=$ estimated regression coefficient.

${ }^{5}$ Ref $=$ reference category.

${ }^{6}$ Coefficient of variation $(\mathrm{CV})=\mathrm{SD}$ over $7 \mathrm{~d}$ /average over $7 \mathrm{~d}$; coefficients $(\beta)$ are per 1-point increase in CV; pef $=$ physical effectiveness factor measured as the sum of the DM proportions retained on the top 2 Penn State particle sieves.

this observational study are not without limitations; however, given the lack of published data, studies of this nature provide a basis for understanding current industry benchmarks and stimulating research in a more controlled setting. For example, in recently published work, researchers tested the effect of short-term changes in silage DM content on the productivity of dairy cows and found only minor effects (McBeth et al., 2013). Research of this nature is necessary for understanding associations that are reported in field studies where extraneous factors may play a large role in the analysis and interpretation of findings. As such, future research directed in a controlled setting is needed to fully understand and interpret the findings presented in this study.

Unmeasured variables, including individual ingredient variability, sample error, and daily variability in batch preparation, may limit interpretation of our results. Potential sources of variation in TMR include variability within individual ingredients, errors in TMR batch preparation, and operator error. In this study, samples of the final TMR were sampled and daily variability in individual ingredients or errors in batch preparation was not recorded. Additionally, financial limitations of this study did not allow for duplicate samples; as such, variability in nutrient analysis in the laboratory could also contribute to the observed level of variability. Sampling protocol was established to ensure consistent sampling between those collecting data, but errors in sampling may have contributed to the level of variability observed. Future research regarding consistency between samples, as well as consistency between observers, is needed to substantiate the associations found in this study. Despite these overall weaknesses, it is clear that TMR variability exists in commercial operations and future research in a controlled setting may be better suited for determining if these associations are, in fact, causal.

\section{CONCLUSIONS}

Examination of the rations fed on 22 commercial freestall farms indicates that dairy producers need to be more aware of the daily variability in TMR composition and take more proactive measures to ensure that the ration delivered is representative of that formulated by the nutritionist. Overall, day-to-day variability was lower than the variability observed between fed and formulated rations. However, variability in daily TMR composition was associated with measures of groupaverage DMI, milk yield, and efficiency. As an example, greater DMI, milk yield, and efficiency of milk production were associated with less variability in energy content of the ration. Lower variability in percent long particles in the offered TMR was associated with greater milk yield and efficiency of milk production. Thus, measures to improve TMR composition, in relation to daily variability, may lead to improvements in DMI, milk yield, and efficiency of group-housed dairy cows, ultimately increasing herd profitability.

\section{ACKNOWLEDGMENTS}

We thank the producers involved in the project for their continued interest and support. We also thank 
CanWest DHI (Guelph, ON, Canada) for their cooperation and for facilitating producer enrollment in the study. We thank technical staff and students at the University of Guelph, Kemptville Campus, for their role in data collection and processing: Megan Bruce, Alexa Main, Nancy Stonos, John Wynands, and Morgan Overvest. Dairy Farmers of Canada (Ottawa, ON, Canada), the Canadian Dairy Commission (Ottawa, ON, Canada), and Agriculture and Agri-Food Canada (Ottawa, ON, Canada) provided financial support for this study. Additional project support was received from the Ontario Ministry of Agriculture, Food and Rural Affairs (OMAFRA; Guelph, ON, Canada), the Canadian Foundation for Innovation (CFI; Ottawa, ON, Canada) and the Ontario Research Fund (Toronto, ON, Canada).

\section{REFERENCES}

AOAC International. 2000. Official Methods of Analysis. Vol. I. 17th ed. AOAC International, Arlington, VA.

Buckmaster, D. R., and L. D. Muller. 1994. Uncertainty in nutritive measures of mixed livestock rations. J. Dairy Sci. 77:3716-3724.

Castillo, A. R., N. R. St-Pierre, N. Silva del Rio, and W. P. Weiss. 2013. Mineral concentrations in diets, water, and milk and their value in estimating on-farm excretion of manure minerals in lactating dairy cows. J. Dairy Sci. 96:3388-3398.

Colmenero, J. J., and G. A. Broderick. 2006. Effect of dietary crude protein concentration on milk production and nitrogen utilization in lactating dairy cows. J. Dairy Sci. 89:1704-1712.

Coppock, C. E., D. L. Bath, and B. Harris Jr. 1981. From feeding to feeding systems. J. Dairy Sci. 64:1230-1249.

Cox, B. G. 2007. Impact of precision feeding strategies on whole farm nutrient balance and feeding management. MS Thesis. Virginia Polytechnic Institute and State University, Blacksburg.

DeVries, T. J., F. Dohme, and K. A. Beauchemin. 2008. Repeated ruminal acidosis challenges in lactating dairy cows at high and low risk for developing acidosis: Feed sorting. J. Dairy Sci. 91:39583967.

Dohoo, I., W. Martin, and H. Stryhn. 2009. Veterinary Epidemiologic Research. 2nd ed. VER Inc., Charlottetown, PEI, Canada.

James, R. E., and B. Cox. 2008. Feeding management to reduce the environmental impact of dairy farms. Pages 31-42 in Proc. 45th Florida Dairy Prod. Conf., University of Florida, Gainesville. University of Florida, Gainesville.
Kononoff, P. J., A. J. Heinrichs, and D. R. Buckmaster. 2003. Modification of Penn State forage and total mixed ration particle separator and the effects of moisture content on its measurements. J. Dairy Sci. 86:1858-1863.

Leonardi, C., and L. E. Armentano. 2003. Effect of quantity, quality, and length of alfalfa hay on selective consumption by dairy cows. J. Dairy Sci. 86:557-564.

Leonardi, C., F. Giannico, and L. E. Armentano. 2005. Effect of water addition on selective consumption (sorting) of dry diets by dairy cattle. J. Dairy Sci. 88:1043-1049.

McBeth, L. R., N. R. St-Pierre, D. E. Shoemaker, and W. P. Weiss. 2013. Effects of transient changes in silage dry matter concentration on lactating dairy cows. J. Dairy Sci. 96:3924-3935.

Mertens, D. R. 1997. Creating a system for meeting the fiber requirements of dairy cows. J. Dairy Sci. 80:1463-1481.

Mikus, J. H. 2012. Diet consistency: Using TMR audits ${ }^{\mathrm{TM}}$ to deliver more from your feed, equipment, and people to the bottom line. Pages 27-36 in High Plains Dairy Conference Proceedings, Amarillo, TX. Texas Animal Nutrition Council, Dallas, TX.

Miller-Cushon, E. K., and T. J. DeVries. 2009. Effect of dietary dry matter concentration on the sorting behavior of lactating dairy cows fed a total mixed ration. J. Dairy Sci. 92:3292-3298.

NRC. 2001. Nutrient Requirements of Dairy Cattle. 7th rev. ed. National Academic Press, Washington, DC.

SAS Institute. 2009. SAS User's Guide. Version 9.2. SAS Institute Inc., Cary, NC.

Silva-del-Rio, N., and A. R. Castillo. 2012. Degree of agreement between the ration formulated and the ration fed on seven California dairies. J. Dairy Sci. 95(E. Suppl. 2):579. (Abstr.)

Sova, A. D., S. L. LeBlanc, B. W. McBride, and T. J. DeVries. 2013. Associations between herd-level feeding management practices, feed sorting, and milk production in free-stall dairy farms. J. Dairy Sci. 96:4759-4770.

Stone, B. 2008. Reducing the variation between formulated and consumed rations. Adv. Dairy Technol. 20:145-162.

Tylutki, T. P., D. G. Fox, and M. McMahon. 2004. Implementation of nutrient management planning on a dairy farm. Prof. Anim. Sci. 20:58-65.

Van Soest, P. J., J. B. Robertson, and B. A. Lewis. 1991. Methods for dietary fiber, neutral detergent fiber and nonstarch polysaccharide in relation to animal nutrition. J. Dairy Sci. 74:3583-3597.

Weiss, W. P., and N. R. St-Pierre. 2009. Impact and management of variability in feed and diet composition. Pages 83-96 in Tri-State Dairy Nutrition Conf. Proc., Fort Wayne, Indiana. Michigan State University, East Lansing; Purdue University, West Lafayette, IN; The Ohio State University, Columbus.

Yang, W. Z., and K. A. Beauchemin. 2006. Increasing the physically effective fiber content of dairy cow diets may lower efficiency of feed use. J. Dairy Sci. 89:2694-2704. 